\title{
Polymorphism in Integrin ITGA2 is Associated with Ischemic Stroke and Altered Serum Cholesterol in Chinese Individuals
}

\author{
Jian-Xia Lu ${ }^{1}$, Zhong-Qian Lu ${ }^{2}$, Shao-lan Zhang ${ }^{1}$, Juan Zhi ${ }^{1}$, Zheng-Ping Chen ${ }^{1}$, Wan-Xiang Wang ${ }^{3}$ \\ 'Department of Medical Technology, Yancheng Health Vocational and Technical College, Yancheng, Jiangsu, P.R. China. \\ ${ }^{2}$ The Intensive Care Unit, the First People's Hospital of Yancheng City, Yancheng, Jiangsu, P.R. China \\ ${ }^{3}$ Department of Laboratory Medicine, the First People's Hospital of Yancheng City, Yancheng, Jiangsu, P.R. China.
}

\begin{abstract}
Background: Recent studies have reported contrasting results regarding the association of polymorphisms in two integrin genes, ITGA2 and ITGB3, with ischemic stroke.

Aims: The present study aimed to investigate the correlation between the ITGA2 C807T and ITGB3 T176C polymorphic loci with ischemic stroke, as well as plasma lipid and lipoprotein levels.

Study Design: Case control study.

Methods: Human venous blood samples were collected from patients admitted for ischemic stroke ( $\mathrm{n}=350$, 'patients') and healthy individuals ( $\mathrm{n}=300$, 'controls'). Blood was genotyped at these loci by polymerase chain reaction-restriction fragment length polymorphism. Plasma lipid and lipoprotein levels were measured by routine enzymatic, masking, and turbidimetry methods.
\end{abstract}

Results: As expected, total cholesterol, triglycerides, and low-density lipoprotein were all significantly higher in patients than in controls $(p<0.05)$. Genotype and allele frequencies of ITGA2 C807T were significantly different between patients and controls $(\mathrm{p}<0.05)$, but no difference was detected in genotype or allele frequencies for ITGA3 T176C. For ITGA-2, the T allele conferred a 1.226 times higher relative risk of ischemic stroke than the $\mathrm{C}$ allele (odds ratio $=1.226,95 \%$ confidence interval $=1.053-1.428$ ). Similarly, total cholesterol was higher in $T$ allele carriers than in non-carriers $(\mathrm{p}<0.05)$.

Conclusion: ITGA2 C807T polymorphism is associated with ischemic stroke, with the $\mathrm{T}$ allele acting as a susceptibility allele that appears to confer increased cholesterol levels. (Balkan Med J 2014;31:55-59).

Key Words: Gene polymorphism, Integrin $\alpha 2$, Integrin $\beta 3$, ischemic stroke, plasma lipid
Ischemic stroke commonly affects older individuals in China and worldwide. Such events are caused by a blood clot that blocks a vessel supplying blood to the brain. However, the etiology and pathogenesis of ischemic stroke are not fully understood. Genetics may play an important role in these events; indeed, rapid progress through the Human Genome Project has allowed the localisation and identification of genes related to ischemic stroke (1). Some single-gene disorders such as Fabry disease and sickle cell disease include ischemic stroke as a feature of the disorder, while in other cases, genetic variants appear to increase individual susceptibility to ischemic events.

Polymorphisms in the members of the integrin family of genes, specifically integrin alpha-2 (ITGA2) and integrin beta-3 (ITGB3), are associated with thrombotic and arterial atherosclerotic disease $(2,3)$. Integrins are adhesion molecules that promote platelet aggregation, contributing to the development of blood clots (4). This function makes them intriguing candidates for the pathogenesis of ischemic stroke. Several polymorphisms have been identified in ITGA2 and ITGB3, but two, a C807T polymorphism (rs1126643 in ITGA2) and a T176C polymorphism (rs5918 in ITGB3), are associated with myocardial infarction and cerebral infarction $(5,6)$. Reiner et al. (7) found that ITGA2 C807T polymorphism was correlated with cerebral stroke in young women, and thus proposed that the $\mathrm{T}$ allele might be a hereditary susceptibility allele predisposing young women t o cerebral stroke. Similarly, Maakaroun et al. (8) found, through investigation on the ITGA2 C807T polymorphism in young twins, that the 807T allele was more frequent in twins with stroke than in those without stroke. However, Nikolopoulos et al. (5) found no correlation between the ITGA2 C807T polymorphism and incidence of ischemic stroke. Because genetic polymorphisms can differ between races/ethnicities, and few studies have been performed to date on ITGA2 and ITGB3 polymorphisms and ischemic stroke, it remains unclear whether ITGA2 C807T is related to ischemic stroke (9).

We hypothesised that polymorphisms in ITGA2 and ITGB3 could increase susceptibility to ischemic stroke in 
Chinese individuals by an association with altered blood chemistry. In this study, the association of ITGA2 and ITGB3 polymorphisms with ischemic stroke was determined by using polymerase chain reaction-restriction fragment length polymorphism (PCR-RFLP) in a Chinese population. Additionally, blood lipids which, when elevated, can contribute to ischemic events were compared among genotypes to provide a theoretical basis for the pathogenesis of ischemic stroke through integrin polymorphisms.

\section{MATERIAL AND METHODS}

\section{Participants}

From February 2010 to February 2012, patients admitted to the First People's Hospital of Yancheng City (Affiliated Hospital of Yancheng Health Vocational \& Technical College) for ischemic stroke were selected as the study population ('patient' group, $\mathrm{n}=350$ ). This group included 207 males and 143 females, aged 35-76 years (mean age, $55.7 \pm 12.2$ years), with 132 cases with a smoking history and 153 with an alcohol consumption history. Diagnosis was made according to the Fourth National Cerebrovascular Disease Diagnostic Criteria (10), and all patients were confirmed by clinical symptoms and brain Computed Tomography (CT) or Magnetic Resonance Imaging (MRI) scan. The study criteria excluded patients with cardiogenic stroke and any strokes caused by arteritis, trauma, blood disease, medication, tumours, cerebral vascular malformation, or aneurysm. A control group comprised 300 healthy people who received physical examination in our hospital during the same time period. This group included 184 males and 116 females, aged 32-73 years (mean age, $54.6 \pm 11.0$ years). The control group excluded individuals with the following diseases and conditions: stroke, liver, kidney and blood disease, autoimmune disease, thyroid disease, pregnancy, and cerebrovascular disease history. The two groups were not statistically different in age or gender. The study was approved by the Ethics Committee of the First People's Hospital of Yancheng City (Affiliated Hospital of Yancheng Health Vocational \& Technical College).

\section{Genomic DNA extraction}

Venous blood samples $(3 \mathrm{~mL})$ were collected from each individual into EDTA-K2-treated anticoagulant tubes. A modified sodium iodide method was used to extract leukocyte genomic DNA(11), which was then stored at $-80^{\circ} \mathrm{C}$ until use.

\section{PCR amplification}

ITGA2 and ITGA3 were amplified by PCR. Primers were obtained from Sangon Biological Engineering Co., Ltd. (Shanghai, China). ITGA2 primers were as follows: upstream of C807T, 5'-GCCAATAATCCAAGAGTTGTGTT-3' and downstream, 5'-TATTTTCTTGCATATTGAATTGCTTC-3'; ITGB3 primers were as follows: upstream of T176C, 5'-CTTAGCTATTGGGAAGTGGTAGG-3' and downstream, 5'-ACTGACTTGAGTGACCTGGGAG-3'. Reactions were performed using $2.5 \mathrm{~mL} 10 \times$ PCR buffer, $2.0 \mathrm{~mL} 2.5 \mathrm{mmol} / \mathrm{L}$ dNTPs, 20 pmol upstream primer and 20 pmol downstream primer, $2.0 \mathrm{~mL}$ template DNA, and 1.25 U Taq DNA polymerase, brought to a $25 \mathrm{~mL}$ total reaction volume with sterilised double-distilled water. Amplification proceeded in a thermal cycler (Bio-Rad) under the following conditions: $94^{\circ} \mathrm{C}$ for 5 minutes; $94^{\circ} \mathrm{C}$ for 30 seconds, $65^{\circ} \mathrm{C}$ for 45 seconds, and $72^{\circ} \mathrm{C}$ for 45 seconds for 35 cycles; and $72^{\circ} \mathrm{C}$ for 5 minutes.

\section{Restriction digestion}

PCR amplification products were digested with restriction enzymes to identify polymorphisms; $3 \mu \mathrm{L}$ product was combined with 2 U BstBI and MspI (Bio-labs, United Kingdom) to identify ITGA2 C807T and ITGB3 T176C, respectively. Reactions were performed at $37^{\circ} \mathrm{C}$ for 3 hours, then products were identified by electrophoresis on an $8 \%$ polyacrylamide gel stained with ethidium bromide. A gel imaging system was used to visualise products.

\section{Determination of blood lipid profiles}

Enzymatic methods were used to determine serum total cholesterol (TC) and triglycerides (TG) levels. The masking method was used to directly determine high-density lipoprotein cholesterol (HDL-C) and low-density lipoprotein cholesterol (LDL-C) levels. Dual-wavelength immunological transmission turbidimetry was used to determine apolipoprotein (Apo) A and Apo B. All determinations were performed on an OLYMPUS AU1000 automatic biochemical analyser (OLYMPUS Corporation, Japan).

\section{Statistical analysis}

SPSS 13.0 software was used for statistical analyses. Genotype and allele frequencies were calculated with the direct gene counting method of Smith (1957). Congruence between the study objective and Hardy-Weinberg equilibrium and genotype and allele frequencies between groups were analysed with the $\chi^{2}$ test. The degree of relative risk was expressed by the odds ratio (OR) and its $95 \%$ confidence interval (CI). Measurement data are presented as mean \pm standard deviation $(\overline{\mathrm{x}} \pm \mathrm{s})$, and $\mathrm{t}$ test was used to compare inter-group lipid and lipoprotein levels. All analyses were two-sided, with $\alpha$ level of 0.05 and $p<0.05$ considered as statistically significant.

\section{RESULTS}

\section{ITGA2 and ITGB3 polymorphisms}

RFLP for the ITGA2 C807T polymorphism produced three possible allele combinations: CC (two bands, $110 \mathrm{bp}$ and $27 \mathrm{bp}$; band $27 \mathrm{bp}$ ran out of the gel), CT (three bands, $137 \mathrm{bp}$, $110 \mathrm{bp}$, and $27 \mathrm{bp}$; band $27 \mathrm{bp}$ ran out of the gel); or TT (one band, 137 bp), as shown in Figure 1a. Similarly, RFLP for the ITGB3 T176C polymorphism produced three possible allele combinations: TT (one band, $256 \mathrm{bp}$ ), TC (three bands, 256 bp, $154 \mathrm{bp}$, and $102 \mathrm{bp}$ ), or CC (two bands, $154 \mathrm{bp}, 102 \mathrm{bp}$; not detected in this study), as shown in Figure $1 b$.

The distribution of ITGA2 and ITGB3 genotypes within both the control and patient groups reached Hardy-Weinberg equilibrium. However, $\chi^{2}$ and correlation analyses revealed significant differences between the two groups in the distribution of the ITGA2 C807T genotype and allele frequencies $(\mathrm{p}<0.05)$. Additionally, relative risk analysis of allele frequency showed 
a

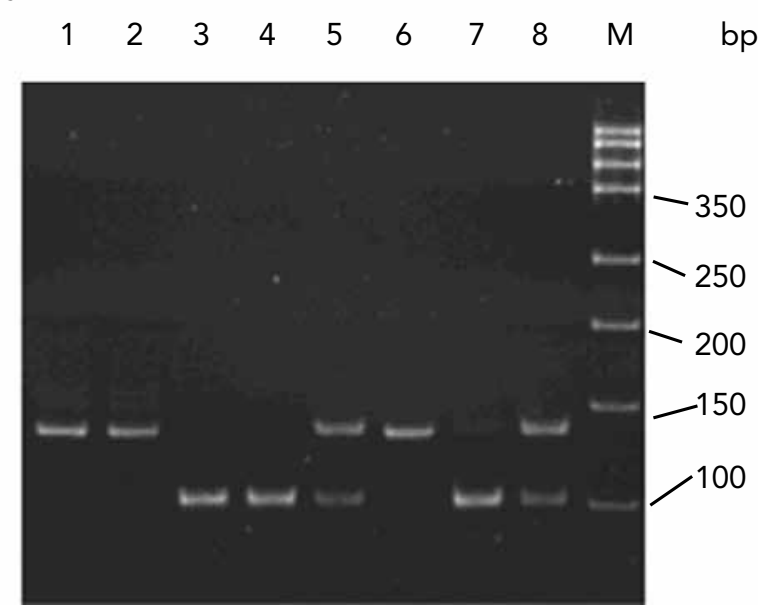

\section{b}

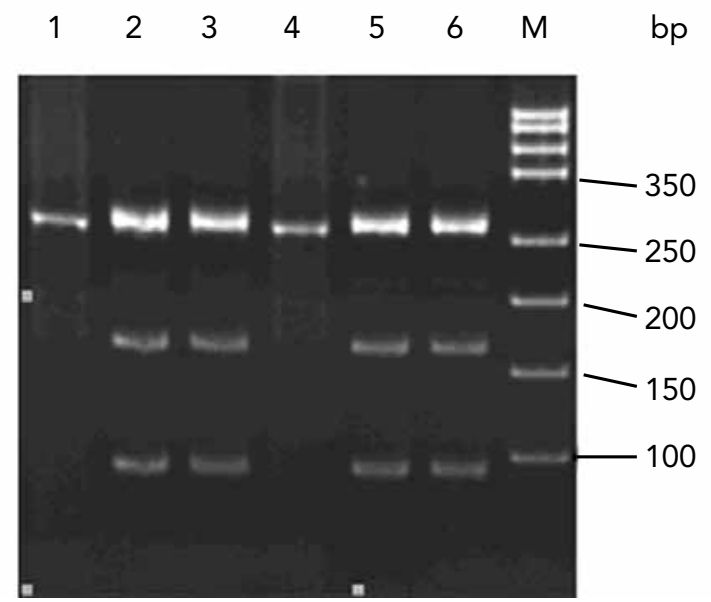

FIG. 1. a, b. Genotyping of ITGA2 C807T and ITGB3 T176C by PCR-RFLP. Genotyping of the ITGA2 C807T polymorphism was performed by PCRRFLP (a); lane M: DNA marker; lanes 1, 2, and 6: TT genotype; lanes 3, 4, and 7: CC genotype; lanes 5 and 8: CT genotype. Genotyping of the ITGB3 T176C polymorphism was performed by PCR-RFLP (b); Lane M: DNA marker; lanes 1 and 4: TT genotype; lanes 2, 3, 5, and 7: TC genotype

that patients with the $\mathrm{T}$ allele were 1.226 times more likely to suffer from ischemic stroke than patients with the $\mathrm{C}$ allele $(\mathrm{OR}=1.226,95 \% \mathrm{CI}=1.053-1.428)$ (Table 1). In contrast, no significant difference was observed in the genotype or allele frequencies for ITGB3 T176C between the two groups (Table 2).

\section{Blood lipid profiles}

In patients suffering from ischemic stroke, mean serum TC, TG, and LDL-C levels were all significantly higher than in the control group $(\mathrm{p}<0.05)$; serum HDL-C, Apo A, and Apo $\mathrm{B}$ were not different (Table 3). The mean TC levels of patients carrying the $\mathrm{T}$ allele at ITGA2 807 (CT and TT genotypes) were significantly higher compared with those of patients carrying the CC genotype $(\mathrm{p}<0.05)$, but TG, LDL-C, HDL-C, Apo A, and Apo B levels were not different (Table 4). Blood lipid profiles were not significantly different between TT and TC genotypes in ITGB3 (Table 5).

\section{DISCUSSION}

Adhesion molecules are glycoproteins that can mediate interactions among cells or between cells and the extracellular matrix. These proteins can aid white blood cells and platelets in adhering to the vascular endothelium, thereby facilitating the formation of cerebral atherosclerotic plaques (12). As two key members of the integrin family of adhesion molecules, ITGA2 and ITGB3 are able to mediate cell-cell, cell-matrix, and cell-matrix-cell adhesions. These proteins, therefore, play important roles in the physiological and pathological processes of inflammatory reaction, immune response, atherosclerosis, thrombosis, etc. $(13,14)$. Studies have indeed associated
TABLE 1. Genotype and allele frequencies for ITGA2 C807T [n (\%)]

\begin{tabular}{lcccccc}
\hline Group & $\mathrm{n}$ & $\mathrm{CC}$ & $\mathrm{TC}$ & $\mathrm{TT}$ & $\mathrm{C}$ & $\mathrm{T}$ \\
\hline Patients & 350 & $148(42.3)$ & $138(39.4)$ & $64(18.3)$ & $434(62.0)$ & $266(38.0)$ \\
Controls & 300 & $139(46.3)$ & $136(45.3)$ & $25(8.3)$ & $414(69.0)$ & $186(31.0)$ \\
$\chi^{2}$ & & & 13.621 & & \multicolumn{2}{c}{6.980} \\
$\mathrm{p}$ & & & 0.001 & & \multicolumn{2}{c}{0.008} \\
\hline
\end{tabular}

TABLE 2. Genotype and allele frequencies for ITGB3 T176C [n (\%)]

\begin{tabular}{lccccc}
\hline Group & $\mathrm{n}$ & $\mathrm{TT}$ & $\mathrm{TC}$ & $\mathrm{T}$ & $\mathrm{C}$ \\
\hline Patients & 350 & $332(94.9)$ & $18(5.1)$ & $682(97.4)$ & $18(2.6)$ \\
Controls & 300 & $289(96.3)$ & $11(3.7)$ & $589(98.2)$ & $11(1.8)$ \\
$\chi^{2}$ & & & 0.826 & \multicolumn{2}{c}{0.880} \\
$\mathrm{p}$ & & & 0.363 & \multicolumn{2}{c}{0.348} \\
\hline
\end{tabular}

ITGA2 and ITGB3 polymorphisms with atherosclerotic diseases (15-17).

Because findings of correlations between ITGA2 and ITGA3 polymorphisms and ischemic stroke have been conflicting, we assessed ITGA2 C807T and ITGB3 T176C polymorphisms in 350 ischemic stroke patients and 300 healthy controls in China. Our findings indicated that ischemic stroke risk was higher in individuals with a $\mathrm{T}$ allele, suggesting that the $\mathrm{T}$ allele may be a hereditary susceptibility gene for cerebral stroke. To understand the potential mechanistic contribution of the ITGA2 C807T polymorphism to stroke, we also investigated differences in blood lipid levels. Elevated blood lipids, particularly LDL-C and TG, contribute to the formation of atherosclerotic plaques and the inflammatory process that can lead to stroke. Unsurprisingly, patients suffering from ischemic stroke exhibited higher levels of TC, TG, and LDL-C than controls. Further, the ITGA2 C807T polymorphism affected blood lipid levels, 
TABLE 3. Blood lipid profiles for ischemic stroke patients and controls

\begin{tabular}{lccccccc}
\hline Group & $\mathrm{n}$ & $\begin{array}{c}\mathrm{TC} \\
(\mathrm{mmol} / \mathrm{L})\end{array}$ & $\begin{array}{c}\text { TG } \\
(\mathrm{mmol} / \mathrm{L})\end{array}$ & $\begin{array}{c}\text { LDL-C } \\
(\mathrm{mmol} / \mathrm{L})\end{array}$ & $\begin{array}{c}\text { HDL-C } \\
(\mathrm{mmol} / \mathrm{L})\end{array}$ & $\begin{array}{c}\text { Apo A } \\
(\mathrm{g} / \mathrm{L})\end{array}$ & $\begin{array}{c}\text { Apo B } \\
(\mathrm{g} / \mathrm{L})\end{array}$ \\
\hline Patients & 350 & $5.44 \pm 0.58$ & $1.78 \pm 0.29$ & $3.41 \pm 1.14$ & $1.28 \pm 0.30$ & $1.13 \pm 0.28$ \\
Controls & 300 & $4.46 \pm 0.85$ & $1.39 \pm 0.30$ & $2.48 \pm 0.85$ & $1.30 \pm 0.29$ & $1.11 \pm 0.28$ & $1.12 \pm 0.28$ \\
$\mathrm{t}$ & & 17.494 & 17.014 & 11.648 & 1.037 & 1.393 & 0.543 \\
$\mathrm{p}$ & & 0.001 & 0.001 & 0.001 & 0.300 & 0.164 \\
\hline
\end{tabular}

TABLE 4. Blood lipid profiles for patients with ischemic stroke according to genotype at ITGA2 C807T

\begin{tabular}{lccccccc}
\hline Genotypes & $\mathrm{n}$ & $\begin{array}{c}\mathrm{TC} \\
(\mathrm{mmol} / \mathrm{L})\end{array}$ & $\begin{array}{c}\mathrm{TG} \\
(\mathrm{mmol} / \mathrm{L})\end{array}$ & $\begin{array}{c}\text { LDL-C } \\
(\mathrm{mmol} / \mathrm{L})\end{array}$ & $\begin{array}{c}\text { HDL-C } \\
(\mathrm{mmol} / \mathrm{L})\end{array}$ & $\begin{array}{c}\text { Apo A } \\
(\mathrm{g} / \mathrm{L})\end{array}$ & $\begin{array}{c}\text { Apo B } \\
(\mathrm{g} / \mathrm{L})\end{array}$ \\
\hline $\mathrm{CC}$ & 148 & $5.35 \pm 0.52$ & $1.81 \pm 0.27$ & $3.38 \pm 1.13$ & $1.27 \pm 0.28$ & $1.14 \pm 0.28$ \\
$\mathrm{CT}+\mathrm{TT}$ & 202 & $5.51 \pm 0.61$ & $1.76 \pm 0.30$ & $3.43 \pm 1.15$ & $1.28 \pm 0.30$ & $1.13 \pm 0.28$ & $1.10 \pm 0.29$ \\
$\mathrm{t}$ & & 2.709 & 1.567 & 0.455 & 0.158 & 0.415 & 0.802 \\
$\mathrm{p}$ & & 0.007 & 0.118 & 0.649 & 0.874 & 0.678 \\
\hline
\end{tabular}

TABLE 5. Blood lipid profiles for patients with ischemic stroke according to genotype at ITGB3 T176C

\begin{tabular}{lccccccc}
\hline Groups & $\mathrm{n}$ & $\begin{array}{c}\mathrm{TC} \\
(\mathrm{mmol} / \mathrm{L})\end{array}$ & $\begin{array}{c}\text { TG } \\
(\mathrm{mmol} / \mathrm{L})\end{array}$ & $\begin{array}{c}\text { LDL-C } \\
(\mathrm{mmol} / \mathrm{L})\end{array}$ & $\begin{array}{c}\text { HDL-C } \\
(\mathrm{mmol} / \mathrm{L})\end{array}$ & $\begin{array}{c}\text { Apo A } \\
(\mathrm{g} / \mathrm{L})\end{array}$ & $\begin{array}{c}\text { Apo B } \\
(\mathrm{g} / \mathrm{L})\end{array}$ \\
\hline TT & 332 & $5.44 \pm 0.57$ & $1.78 \pm 0.29$ & $3.41 \pm 1.15$ & $1.28 \pm 0.29$ & $1.14 \pm 0.28$ \\
TC & 18 & $5.46 \pm 0.67$ & $1.80 \pm 0.20$ & $3.45 \pm 0.83$ & $1.33 \pm 0.34$ & $1.11 \pm 0.26$ & $1.12 \pm 0.28$ \\
$\mathrm{t}$ & & 0.101 & 0.344 & 0.171 & 0.724 & 0.361 & 1.125 \\
$\mathrm{p}$ & & 0.920 & 0.731 & 0.864 & 0.470 & 0.719 \\
\hline
\end{tabular}

with significantly higher TC levels in ischemic stroke patients carrying the $\mathrm{T}$ allele than those with the $\mathrm{C}$ allele. Therefore, individuals with the $\mathrm{T}$ allele have increased $\mathrm{TC}$ that may then increase the likelihood of ischemic stroke.

In contrast, the ITGB3 T176C polymorphism did not lead to significant differences in allele or genotype frequencies or lipid profiles between patients and controls. Therefore, the ITGB3 T176C polymorphism appears to have no correlation with ischemic stroke.

In summary, the ITGA2 C807T polymorphism is correlated with ischemic stroke. In particular, the $\mathrm{T}$ allele may be a hereditary susceptibility allele for cerebral stroke, possibly because the allele leads to increased TC levels.

Ethics Committee Approval: Ethics committee approval was received from the Ethics Committee of the First People's Hospital of Yancheng City (Affiliated Hospital of Yancheng Health Vocational \& Technical College) with No. YCPH (Ethics) 201001003.

Informed Consent: Informed consent was obtained from participants of this study.

Peer-review: Externally peer-reviewed.

Author contributions: Concept - J.L., Z. L.; Design - J.L.; Supervision - S.Z., J.Z.; Resource - Z.L., W.W.; Materials - Z.L., W.W.; Data Collection\&/ or Processing - J.L., Z.C; Analysis\&/or Interpretation - J.L.,Z.C.; Literature Search - J.L., Z.C.; Writing - J.L.; Critical Reviews - S.Z.
Conflict of Interest: No conflict of interest was declared by the authors.

Financial Disclosure: This work was supported by Special Youth Found of Yancheng Health Vocational and Technical College, and Jiangsu Provincial Health Department.

\section{REFERENCES}

1. Meschia JF, Worrall BB, Rich SS. Genetic susceptibility to ischemic stroke. Nat Rev Neurol 2011;7:369-78. [CrossRef]

2. Huo Y, Ley K. Adhesion molecules and atherogenesis. Acta Physiol Scand 2001;173:35-43. [CrossRef]

3. Elkind MS. Inflammation, atherosclerosis, and stroke. Neurologist 2006;12:140-8. [CrossRef]

4. Rivera J, Lozano ML, Navarro-Nú-ez L, Vicente V. Platelet receptors and signaling in the dynamics of thrombus formation. Haematologica 2009;94:700-11. [CrossRef]

5. Nikolopoulos GK, Tsantes AE, Bagos PG, Travlou A, Vaiopoulos G. Integrin, alpha 2 gene $\mathrm{C} 807 \mathrm{~T}$ polymorphism and risk of ischemic stroke:a meta-analysis. Thromb Res 2007;119:501-10. [CrossRef]

6. Wei YS, Lan Y, Liu YG, Meng LQ, Xu QQ, Xie HY. Association of the integrin gene polymorphisms with ischemic stroke and plasma lipid levels. Zhonghua Yi Xue Yi Chuang Xue Za Zhi 2009;26:211-5.

7. Reiner AP, Kumar PN, Schwartz SM, Longstreth WT Jr, Pearce RM, Rosendaal FR, et al. Genetic variants of platelet glycoprotein receptors and risk of stroke in young women. Stroke 2000;31:1628-33. [CrossRef]

8. Maakaroun A, Regina S, Delahousse B, Saudeau D, Gruel Y. Ischemic strokes and homozygosity for the alpha2 $807 \mathrm{~T}$ allele of the platelet collagen receptor in young monozygotic twins. Blood Coagul Fibrinolysis 2003;14:83-5. [CrossRef] 
9. Matarin M, Brown WM, Hardy JA, Rich SS, Singleton AB, Brown RD $\mathrm{Jr}$, et al. Association of integrin alpha gene variants with ischemic stroke. J Cereb Blood Flow Metab 2008;28:81-9. [CrossRef]

10. Xavier UR, Joaquín SL. Stoke, diagnosis and therapeutic management of cerebrovascular disease. Rev Esp Cardiol 2007;60:753-69.

11. Orii KE, Aoyama T, Wakui K, Fukushima Y, Miyajima H, Yamaguchi S, et al. Genomic and Mutational Analysis of the Mitochondrial Trifunctional Protein $\beta$-Subunit (HADHB) Gene in Patients with Trifunctional Protein Deficiency. Hum Mol Genet 1997;6:1215-24. [CrossRef]

12. Hellewell PG. Adhesion molecule strategies. Pulm Pharmacol Ther 1999;12:137-41. [CrossRef]

13. Jacquelin B, Rozenshteyn D, Kanaji S, Koziol JA, Nurden AT, Kunicki TJ. Characterization of Inherited Differences in Transcription of the Human Integrin alpha 2 Gene. J Biol Chem 2001;276:23518-24. [CrossRef]
14. Vijayan KV, Liu Y, Dong JF, Bray PF. Enhanced activation of mitogen-activated protein kinase and myosin light chain kinase by the Pro33 polymorphism of integrin beta 3. J Biol Chem 2003;278:3860-7. [CrossRef]

15. Payne KE, Bray PF, Grant PJ, Carter AM. Beta3 integrin haplotype influences gene regulation and plasma von Willebrand factor activity. Atherosclerosis 2008;198:280-6. [CrossRef]

16. Manginas A, Tsiavou A, Chaidaroglou A, Giamouzis G, Degiannis D, Panagiotakos $\mathrm{D}$, et al. Inflammatory cytokine gene variants in coronary artery disease patients in Greece. Coron Artery Dis 2008;19:575-82. [CrossRef]

17. Giusti B, Gori AM, Marcucci R, Sestini I, Saracini C, Paniccia R, et al. Role of glycoprotein Ia gene polymorphisms in determining platelet function in myocardial infarction patients undergoing percutaneous coronary intervention on dual antiplatelet treatment. Atherosclerosis 2008;196:341-8. [CrossRef] 